\title{
Optimal timing of endoscopic retrograde cholangiopancreatography for acute cholangitis associated with distal malignant biliary obstruction
}

Namyoung Park, Sang Hyub Lee* ${ }^{*}$, Min Su You, Joo Seong Kim, Gunn Huh, Jung Won Chun, In Rae Cho, Woo Hyun Paik, Ji Kon Ryu and Yong-Tae Kim

\begin{abstract}
Background: There is a lack of studies regarding the optimal timing for endoscopic retrograde cholangiopancreatography (ERCP) in patients with cholangitis caused by distal malignant biliary obstruction (MBO). This study aims to investigate the optimal timing of ERCP in patients with acute cholangitis associated with distal MBO with a naïve papilla.

Methods: A total of 421 patients with acute cholangitis, associated with distal MBO, were enrolled for this study. An urgent ERCP was defined as being an ERCP performed within $24 \mathrm{~h}$ following emergency room (ER) arrival, and early ERCP was defined as an ERCP performed between 24 and $48 \mathrm{~h}$ following ER arrival. We evaluated both 30-day and 180-day mortality as primary outcomes, according to the timing of the ERCP.

Results: The urgent ERCP group showed the lowest 30-day mortality rate (2.2\%), as compared to the early and delayed ERCP groups $(4.3 \%$ and $13.5 \%)(P<0.001)$. The 180 -day mortality rate was lowest in the urgent ERCP group, followed by early ERCP and delayed ERCP groups (39.4\%, 44.8\%, 60.8\%; $P=0.006)$. A subgroup analysis showed that in both the primary distal MBO group, as well as in the moderate-to-severe cholangitis group, the urgent ERCP had significantly improved in both 30-day and 180-day mortality rates. However, in the secondary MBO and mild cholangitis groups, the difference in mortality rate between urgent, early, and delayed ERCP groups was not significant.
\end{abstract}

Conclusions: In patients with acute cholangitis associated with distal $\mathrm{MBO}$, urgent ERCP might be helpful in improving the prognosis, especially in patients with primary distal MBO or moderate-to-severe cholangitis.

Keywords: Cholangitis, Endoscopic retrograde cholangiopancreatography, Neoplasms, Early intervention, Treatment outcomes

*Correspondence: gidoctor@snuh.org

Division of Gastroenterology, Department of Internal Medicine, Liver

Research Institute, College of Medicine, Seoul National University

Hospital, Seoul National University, 101, Daehak-ro, Jongno-gu,

Seoul 03080, Republic of Korea

\begin{abstract}
Background
Acute cholangitis is an infection of biliary system as a result of biliary stasis [1]. This can be life-threatening without timely intervention, such as biliary drainage and adequate antibiotics [1-5]. Early endoscopic retrograde cholangiopancreatography (ERCP) done within $48 \mathrm{~h}$ in patients with moderate-to-severe cholangitis is known to reduce the duration of hospitalization, mortality rates,
\end{abstract}


and adverse events, such as multiple organ failure [3-7]. The most common cause of obstruction is choledocholithiasis, which accounts for about half of the cases [7-9]. Malignant biliary obstruction (MBO), such as pancreatic cancer, cholangiocarcinoma, or metastatic cancer, constitutes $10-30 \%$ of cholangitis cases [3, 5, 7-9].

Patients with biliary stones and those with $\mathrm{MBO}$ show different clinical courses and prognoses. Cholangitis caused by biliary stones can be definitely treated by biliary drainage and removing the stones [10]. On the other hand, patients with malignant biliary stricture require additional treatment for the underlying disease following adequate biliary decompression. Because patients with $\mathrm{MBO}$ are usually treated with chemotherapy for the underlying disease, most patients have poor oral intake, poor performance status, and are susceptible to infection [11-13]. According to a recent study of patients with acute cholangitis by Parikh et al. [14] MBO is associated with a higher risk of readmission within 30 days. MBO is often combined with anatomical alteration in the gastrointestinal tract, which can make insertion and cannulation difficult $[15,16]$. The stage of cancer also affects the prognosis. Unlike patients with early-stage cancer, which can be treated curatively, the prognosis for patients with MBO caused by metastatic cancer is worse, regardless of adequate biliary drainage [17].

Previous studies emphasizing the role of early ERCP have been based on populations with heterogeneous etiologies and mostly included patients with biliary stones $[8,18,19]$. In a study by Tan et al. [19] $45 \%$ of all cholangitis was caused by common bile duct stones, and $43 \%$ by MBO. Another study by Kiriyama et al. [8] is based on patients with various etiologies. The current Tokyo Guidelines recommend early or urgent ERCP, depending on the severity, but they do not mention the etiology [20].

To date, there is a lack of studies regarding the optimal timing for ERCP in patients with cholangitis caused by distal MBO. The purpose of this study is to evaluate the outcomes according to the timing of ERCP in patients with acute cholangitis due to distal MBO.

\section{Methods}

\section{Patients and enrollment criteria}

This is a retrospective study at Seoul National University Hospital. From January 2005 to June 2018, we analyzed 1,804 patients who had visited the emergency room (ER) and had undergone ERCP for suspected biliary obstruction. The 10th edition of the International Classification of Diseases (ICD-10) codes and pathologic reports were reviewed to identify patients with MBO. Patients with biliary stones or other benign etiologies were excluded. Patients who had been discharged from the ER right after ERCP and had received outpatient department-based treatment were also excluded. We identified 754 patients as MBO patients with a naïve papilla after we had excluded those who had previously undergone endoscopic sphincterotomy, percutaneous transhepatic biliary drainage, or endoscopic ultrasound-guided biliary drainage. After excluding patients with hilar obstruction and those without cholangitis, a total of 421 patients were included (Fig. 1). This study was approved by the Institutional Review Board of Seoul National University Hospital, Seoul, Korea (1802-123-924).

\section{Data collection and definitions}

Demographic data, including age, sex, and comorbidities was collected. Patient complaints were investigated at the time of ER arrival, and vital signs, including blood pressure, body temperature, respiratory rate, heart rate, and oxygen saturation were measured. Laboratory findings, including white blood cell count, platelet count, C-reactive protein, total bilirubin, albumin, aspartate transaminase, alanine transaminase, alkaline phosphatase, gamma glutamyl transpeptidase, creatinine, and prothrombin time were obtained. If, based on the patient's symptoms and laboratory findings, the biliary tract obstruction was suspicious, computed tomography scans covering the biliary tree were performed. The diagnosis of $\mathrm{MBO}$ was based on the obstructive patterns of the liver function test, concurrent with bile duct strictures on the imaging findings. Cholangitis was defined and graded according to the 2018 Tokyo Guidelines [20]. Previous anticancer treatments, such as curative surgery, chemotherapy, or radiation therapy were investigated. Following ERCP, the cancer status was assessed, and treatment types, including surgery and palliative chemotherapy, were investigated. Death data was collected from the Korean Ministry of the Interior and Safety database.

Urgent ERCP was defined as ERCP performed within $24 \mathrm{~h}$, and early ERCP was defined as ERCP performed between 24 to $48 \mathrm{~h}$ following ER arrival [20]. ERCP performed after $48 \mathrm{~h}$ was defined as delayed ERCP [21]. The physicians decided when to perform ERCP based on the condition of patients including the moderate to severe cholangitis. $\mathrm{MBO}$ was classified as primary and secondary distal $\mathrm{MBO}$, according to the origin of biliary obstructive lesion. Primary distal MBO was defined as a cancer originally located in the pancreatic head, bile duct, ampulla of Vater, periampullary duodenum, or the gallbladder directly invading the mid-to-distal CBD; whereas secondary distal MBO was defined as any other cancer with metastasis to the peribiliary lymph nodes and soft tissues. 
ER Patients suspicious of biliary obstruction

$\mathrm{N}=1804$

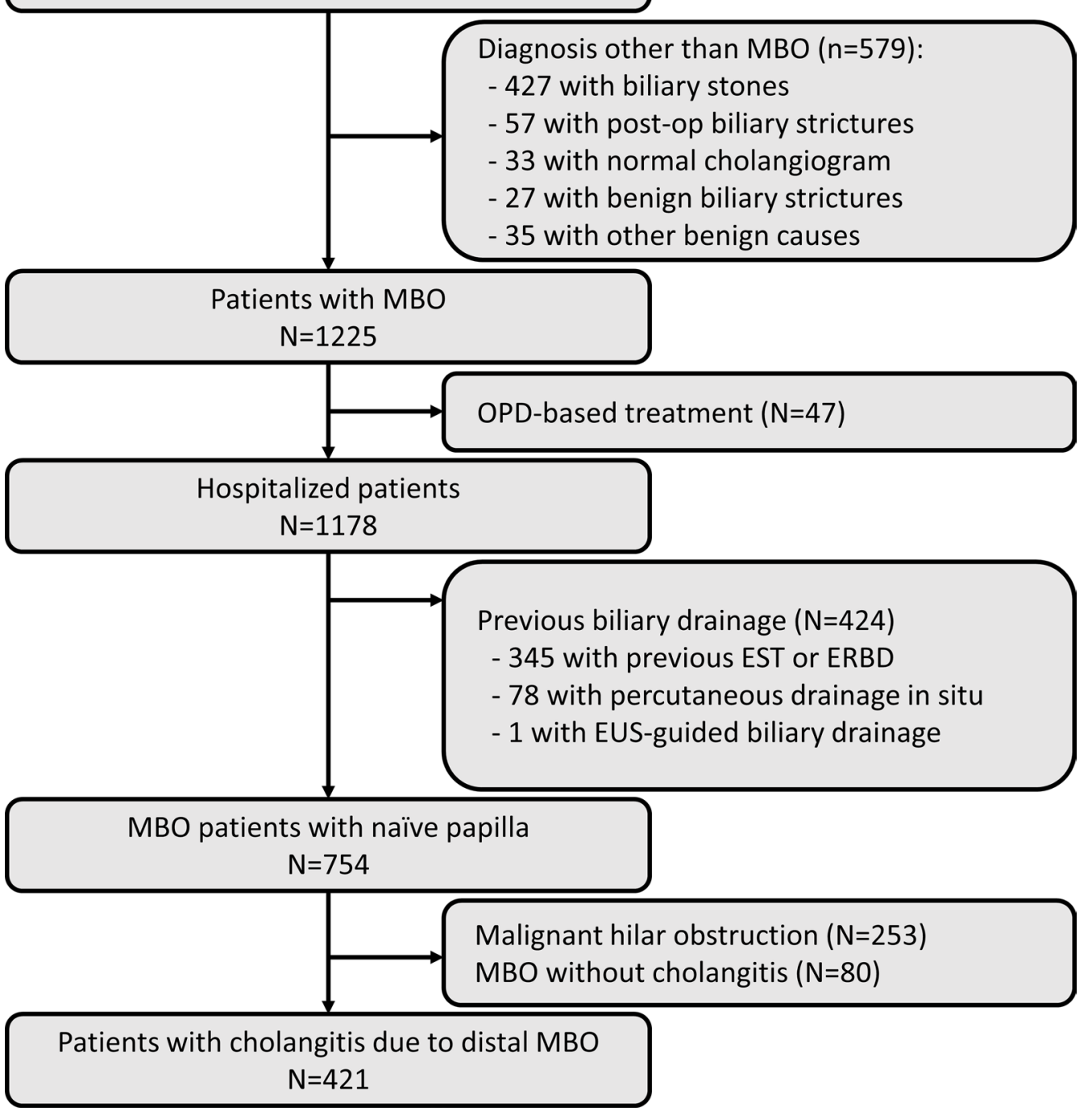

Fig. 1 Flowchart of patient enrollment

\section{Procedures}

All ERCPs were performed under moderate sedation using midazolam and meperidine. Side-viewing duodenoscopes were used (TJF-260, JF-260, TJF-240, JF-240, TJF-200, and JF-200; Olympus Optical, Tokyo, Japan). After cannulation of the ampulla of Vater, sphincterotomy was performed at the discretion of the performing clinicians. Contrast was injected after the cannulation, and fluoroscopic findings were obtained to evaluate the biliary tree. Once the obstructive level had been identified, the clinician passed guidewire to the upstream part of the bile duct obstruction, and inserted a plastic stent and/or self-expandable metal stent. If a tight biliary stricture was expected, the stent was inserted following balloon dilatation at the stricture site.

\section{Study outcome measures}

The primary study outcomes were the 30-day mortality rate and the 180-day mortality rate between those patients who had undergone urgent, early or delayed ERCP. Secondary outcomes were the technical success rate, the clinical success rate, differences in hospital stay, and postprocedural adverse events, such as pancreatitis, bleeding, and perforation. Technical success was defined as a successful deployment of biliary stents at the stricture site on the first ERCP. Clinical success was defined 
as $\geq 30 \%$ decrease in total bilirubin over a four-week period [22]. Post-ERCP adverse events were based on the lexicon guidelines of the American Society for Gastrointestinal Endoscopy [23].

\section{Statistical analysis}

Continuous variables were expressed as a mean ( \pm standard deviation) or a median (with interquartile range), and categorical variables as numbers and percentages. Student's t test, pairwise Wilcoxon rank sum test, or Kruskal-Wallis rank sum test was used for comparison of continuous variables between the groups. Pearson's chisquare test or Fisher's exact test was used for comparison of categorical value. Post hoc analysis was performed using the Bonferroni method. In addition, a multivariable analysis was conducted to assess the possible risk factors for primary outcomes with $p$-values $\leq 0.1$ in the univariable analysis and to adjust for age, sex and ER visit during holidays. Akaike Information Criterion-based backward selection was used in the multivariable logistic regression analysis [24]. All statistical analyses were conducted using the $\mathrm{R} \mathrm{s} / \mathrm{w}$ environment (version 3.6.3; The R Foundation for Statistical Computing, Vienna, Austria), and a $P$-value $<0.05$ was considered to be statistically significant.

\section{Results}

\section{Baseline characteristics}

Table 1 summarizes the baseline characteristics. Urgent, early, and delayed ERCPs were performed in 231 (54.9\%), $116(27.6 \%)$ and $74(17.6 \%)$ patients, respectively. The median time from ER arrival to ERCP was 24.0 (13.244.7) hours for mild $(n=86), 22.2(7.2-30.6)$ hours for moderate $(n=289)$, and $25.9(18.4-43.4)$ hours for severe $(n=46)$ grade of cholangitis, and there was no significant difference between them $(P=0.087)$. Prior to the initial ERCP, 135 (32.1\%) and $52(12.4 \%)$ patients had received either palliative systemic chemotherapy or curative resection for underlying malignancy, respectively. Among 421 patients, technical success was achieved in 348 patients. Plastic stents were used for 173 patients and metal stents were used for 175 patients. Twelve patients required balloon dilatation for stent insertion due to tight biliary stricture, while no patient received bougination for their biliary stricture.

The median time before the procedure was 23.1 (8.433.0) hours, 11.8 (5.5-20.9) hours in urgent group, 28.6 (25.9-36.4) hours in early group, and 70.9 (53.5-98.8) hours in the delayed ERCP group $(P<0.001)$. There were no significant differences in age, sex, primary cancer location, Charlson's Comorbidity Index (CCI), the proportion of primary $\mathrm{MBO}$, cholangitis severity, the
Table 1 Baseline characteristics

\begin{tabular}{|c|c|}
\hline Variables & $(N=421)$ \\
\hline Age & $67.0(59.0-73.0)$ \\
\hline \multicolumn{2}{|l|}{ Sex } \\
\hline Male & $251(59.6 \%)$ \\
\hline Female & $170(40.4 \%)$ \\
\hline \multicolumn{2}{|l|}{ Etiology of MBO } \\
\hline Biliary tract & $184(43.7 \%)$ \\
\hline Pancreas & $150(35.6 \%)$ \\
\hline Upper Gl tract & $35(8.3 \%)$ \\
\hline Lower Gl tract & $21(5.0 \%)$ \\
\hline Lung & $10(2.4 \%)$ \\
\hline Genitourinary tract & $8(1.9 \%)$ \\
\hline Breast & $6(1.4 \%)$ \\
\hline Liver & $5(1.2 \%)$ \\
\hline Others & $2(0.5 \%)$ \\
\hline \multicolumn{2}{|l|}{ Underlying disease } \\
\hline Hypertension & $192(45.6 \%)$ \\
\hline Diabetes mellitus & $99(23.5 \%)$ \\
\hline Cardiovascular disease & $32(7.6 \%)$ \\
\hline Chronic liver disease & $26(6.2 \%)$ \\
\hline Chronic kidney disease & $5(1.2 \%)$ \\
\hline Chronic obstructive pulmonary disease & $10(2.4 \%)$ \\
\hline Primary MBO & $341(81.0 \%)$ \\
\hline \multicolumn{2}{|l|}{ Cholangitis severity $^{\mathrm{a}}$} \\
\hline Mild & $86(20.4 \%)$ \\
\hline Moderate & $289(68.6 \%)$ \\
\hline Severe & $46(10.9 \%)$ \\
\hline Previous upper Gl surgery & $15(3.6 \%)$ \\
\hline \multicolumn{2}{|l|}{ Initial laboratory findings } \\
\hline White blood cell, $10^{3} / \mu \mathrm{L}$ & $8.0 \pm 3.8$ \\
\hline Platelet, $10^{3} / \mu \mathrm{L}$ & $245.2 \pm 103.1$ \\
\hline$C R P, m g / d L$ & $5.8 \pm 5.7$ \\
\hline Creatinine, mg/dL & $0.8 \pm 0.6$ \\
\hline Albumin, $\mathrm{g} / \mathrm{dL}$ & $3.2 \pm 0.5$ \\
\hline Total bilirubin, mg/dL & $7.9 \pm 6.4$ \\
\hline AST, IU/L & $122.1 \pm 138.9$ \\
\hline ALT, IU/L & $146.8 \pm 134.5$ \\
\hline$A L P, I U / L$ & $461.4 \pm 306.0$ \\
\hline GGT, IU/L & $674.7 \pm 518.8$ \\
\hline PT (INR) & $1.1 \pm 0.2$ \\
\hline
\end{tabular}

$M B O$ malignant biliary obstruction, $G /$ gastrointestinal, $C R P C$-reactive protein, AST aspartate transaminase, ALT alanine transaminase, ALP alkaline phosphatase, GGT gamma glutamyl transpeptidase, $P T$ prothrombin time, INR international normalized ratio

a Was defined according to the Tokyo Guidelines of 2018

type of biliary stent, and the need for balloon dilatation between the three groups. Table 2 summarizes the differences in baseline characteristics between the patients in the urgent, early, and the delayed ERCP groups. 
Table 2 Differences in baseline characteristics between the urgent, early, and elective ERCP groups

\begin{tabular}{|c|c|c|c|c|}
\hline Variables & Urgent ERCP $(N=231)$ & Early ERCP $(\mathrm{N}=116)$ & Delayed ERCP $(\mathrm{N}=74)$ & $P$ value \\
\hline Age & $67.0(59.0-73.0)$ & $67.0(60.0-73.0)$ & $66.0(59.0-72.0)$ & 0.967 \\
\hline Sex & & & & 0.858 \\
\hline Male & $139(60.2 \%)$ & $70(60.3 \%)$ & $42(56.8 \%)$ & \\
\hline Female & $92(39.8 \%)$ & $46(39.7 \%)$ & $32(43.2 \%)$ & \\
\hline $\mathrm{CCl}$ & $5.5 \pm 1.7$ & $5.5 \pm 1.8$ & $5.9 \pm 1.9$ & 0.223 \\
\hline Primary MBO & $189(81.8 \%)$ & $96(82.8 \%)$ & $56(75.7 \%)$ & 0.428 \\
\hline Cholangitis severity $^{\mathrm{a}}$ & & & & 0.536 \\
\hline Mild & $43(18.6 \%)$ & $25(21.6 \%)$ & $18(24.3 \%)$ & \\
\hline Moderate to severe & $188(81.4 \%)$ & $91(78.4 \%)$ & $56(75.7 \%)$ & \\
\hline Previous upper Gl surgery & $10(4.3 \%)$ & $4(3.4 \%)$ & $1(1.4 \%)$ & 0.484 \\
\hline ER arrival at holidays ${ }^{b}$ & $45(19.5 \%)$ & $37(31.9 \%)$ & $48(64.9 \%)$ & $<0.001$ \\
\hline
\end{tabular}

$E R C P$ endoscopic retrograde cholangiopancreatography, $M B O$ malignant biliary obstruction, $G /$ gastrointestinal, $C C I$ Charlson's comorbidity index, $E R$ emergency room

a Was defined according to the 2018 Tokyo Guidelines

b Also included the day before holidays

\section{The differences in 30-day and 180-day mortality rates between each study group}

The 30-day mortality rate was lowest in the urgent ERCP group, followed by the early and delayed ERCP groups $(2.2 \%, 4.3 \%, 13.5 \% ; P<0.001)$. In the post hoc analysis, the 30-day mortality in the urgent ERCP group was significantly lower than in the delayed ERCP group $(P=0.001)$, whereas the difference between early and delayed ERCP groups was not significant $(P=0.084)$. The differences in the 180-day mortality rate between the urgent, early, and delayed ERCP groups were also significant $(39.4 \%, 44.8 \%, 60.8 \% ; P=0.006)$. In the post hoc analysis, the urgent ERCP group showed a significantly lower mortality rate as compared to the delayed ERCP group $(P=0.006)$, but the early ERCP group did not $(P=0.112)$. Figure 2 demonstrates the differences in both the 30-day and 180-day mortality rates in each study group.

Table 3 shows the result of a multivariable analysis, which revealed that urgent ERCP (OR 0.11 [0.03-0.34]; $P<0.001$ ), early ERCP (OR $0.23[0.07-0.75] ; P=0.015$ ) and secondary MBO (OR 3.33 [1.22-9.06]; $P=0.019$ ) are associated with a 30 -day mortality rate. Table 4 demonstrates that a 180-day mortality rate is significantly associated with urgent ERCP (OR 0.41 [0.230.72 ]; $P=0.002$ ), early ERCP (OR 0.54 [0.29-1.00]; $P=0.049$ ), and secondary MBO (OR 4.39 [2.52-7.63]; $P<0.001)$ in the multivariable analysis.

Neither the type of biliary stent $(P=0.145)$ nor the need for biliary dilation $(P=0.560)$ were significantly associated with the 30-day mortality rate. However, the use of metal stent for biliary drainage was associated with the increased 180-day mortality rate (OR 9.99 [6.04-16.52]; $P<0.001)$, while the need for balloon dilatation was not significantly associated with a 180day mortality rate (OR 1.76 [0.55-5.65]; $P=0.340$ ).

Among 20 patients who died within 30 days after ERCP, there were 12 patients whose cause of death could be identified. The most common cause of death was disease progression (8 patients, 66.7\%), followed by infection other than cholangitis (3 patients, 25\%), and uncontrolled benign gastric ulcer bleeding (1 patient, $8.3 \%$ ). The cause of 180-day mortality, however, was hardly identifiable. In most of patients who died within 180 days after ERCP, we were not able to determine the cause of death (137 patients, $72.9 \%$ ).

\section{Subgroup analysis based on the etiology and severity of cholangitis}

In the subgroup analysis, the difference in the 30-day mortality rates between the urgent, early, and delayed ERCP groups was significant in the primary $\mathrm{MBO}$ group $(1.6 \%, 3.1 \%, 10.7 \% ; P=0.007$, Additional file 1$)$ and in the moderate-to-severe cholangitis group $(2.7 \%$, $5.5 \%, 17.9 \% ; P<0.001)$. The 180 -day mortality rates also showed significant differences between the urgent, early, and delayed ERCP groups in the primary $\mathrm{MBO}$ patients (31.7\%, 40.6\%, 53.6\%; $P=0.010$, Additional file 2) and the moderate-to-severe cholangitis patients $(39.9 \%, 49.5 \%$, $62.5 \% ; P=0.009$ ). In the post hoc analysis, the difference between the urgent and delayed ERCP groups was significant in all subgroups. Early ERCP, however, did not show any significant differences from delayed ERCP in all subgroups. Patients with secondary MBO or mild cholangitis did not show significant differences in the 30-day (secondary MBO: $4.8 \%, 10.0 \% 22.2 \% ; P=0.094$, mild cholangitis: $0.0 \%, 0.0 \%, 0.0 \%, P>0.999$ ) and the 180 -day mortality rates within all study groups (secondary $\mathrm{MBO}$ : 

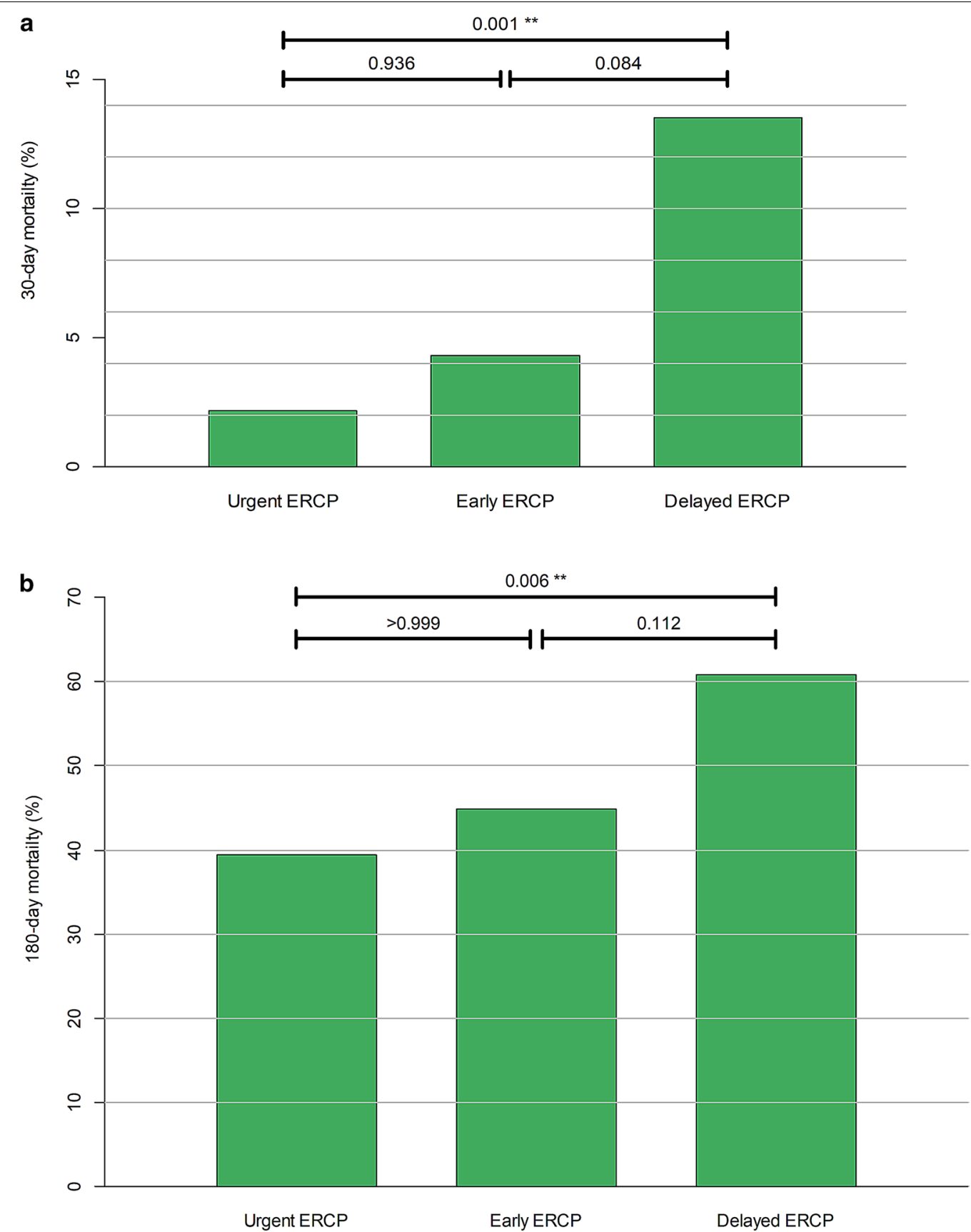

Fig. 2 The difference in 30-day mortality rate (a) and 180-day mortality rate (b) between urgent, early and delayed ERCP groups

73.8\%, $65.0 \% 83.3 \% ; P=0.468$, mild cholangitis: $37.2 \%$, $28.0 \%, 55.6 \% ; P=0.182$ ).

\section{Secondary outcomes according to the timing of ERCP}

Table 5 summarizes the differences in secondary outcomes among the three study groups classified by ERCP timing. The overall technical success rate was $82.7 \%$, and the differences between each ERCP group were not significant $(P=0.120)$. The clinical success rate in the overall cohort was $75.1 \%$, and the urgent ERCP group showed the highest clinical success rate, followed by the early and delayed ERCP groups $(80.1 \%, 75.0 \%$ and $59.5 \% ; P=0.002)$. Adverse events related to the procedure were observed in 31 patients (7.4\%); pancreatitis in $22(5.2 \%)$, bleeding in $8(1.9 \%)$, and perforation in 
Table 3 Univariable and multivariable analysis identifying factors related to 30-day mortality

\begin{tabular}{|c|c|c|c|c|}
\hline & \multicolumn{2}{|l|}{ Univariable } & \multicolumn{2}{|l|}{ Multivariable } \\
\hline & Odds ratio $(95 \% \mathrm{Cl})$ & $P$ value & Odds ratio $(95 \% \mathrm{Cl})$ & $P$ value \\
\hline Age $\geq 75$ & $0.40(0.04-1.70)$ & 0.270 & & \\
\hline Male sex & $2.83(0.93-8.60)$ & 0.095 & $2.88(0.90-9.20)$ & 0.074 \\
\hline \multicolumn{5}{|l|}{ Timing of ERCP } \\
\hline$>48 \mathrm{~h}$ & & & 1 (Reference) & \\
\hline $24-48 h$ & & 0.084 & $0.23(0.07-0.75)$ & 0.015 \\
\hline$<24 \mathrm{~h}$ & & 0.001 & $0.11(0.03-0.34)$ & $<0.001$ \\
\hline Secondary $\mathrm{MBO}$ & $3.04(1.04-8.42)$ & 0.035 & $3.33(1.22-9.06)$ & 0.019 \\
\hline Mild cholangitis & $0.00(0.00-0.76)$ & 0.019 & 0.00 (0.00-infinity) & 0.987 \\
\hline ER arrival at holidays & $1.52(0.61-3.82)$ & 0.511 & & \\
\hline
\end{tabular}

ERCP, endoscopic retrograde cholangiopancreatography; $\mathrm{MBO}$, malignant biliary obstruction, ER: emergency room

Table 4 Univariable and multivariable analysis identifying factors related to 180-day mortality

\begin{tabular}{|c|c|c|c|c|}
\hline & \multicolumn{2}{|l|}{ Univariable } & \multicolumn{2}{|l|}{ Multivariable } \\
\hline & Odds ratio $(95 \% \mathrm{Cl})$ & $P$ value & Odds ratio $(95 \% \mathrm{Cl})$ & $P$ value \\
\hline Age $\geq 75$ & $0.62(0.38-1.00)$ & 0.066 & $0.61(0.36-1.02)$ & 0.060 \\
\hline Male sex & $0.96(0.65-1.42)$ & 0.907 & & \\
\hline \multicolumn{5}{|l|}{ Timing of ERCP } \\
\hline$>48 \mathrm{~h}$ & & & 1 [Reference] & \\
\hline $24-48 h$ & & 0.112 & $0.54(0.29-1.00)$ & 0.049 \\
\hline$<24 h$ & & 0.006 & $0.41(0.23-0.72)$ & 0.002 \\
\hline Secondary MBO & $4.62(2.68-7.95)$ & $<0.001$ & $4.39(2.52-7.63)$ & $<0.001$ \\
\hline Mild cholangitis & $0.72(0.45-1.17)$ & 0.233 & $0.59(0.35-1.01)$ & 0.056 \\
\hline ER arrival at holidays & $0.91(0.60-1.38)$ & 0.742 & & \\
\hline
\end{tabular}

$E R C P$ endoscopic retrograde cholangiopancreatography, $M B O$ malignant biliary obstruction, $E R$ emergency room

Table 5 Secondary outcomes between three groups classified by duration to ERCP

\begin{tabular}{lllll}
\hline & Urgent ERCP $(\mathrm{N}=231)$ & Early ERCP $(\mathrm{N}=116)$ & Delayed ERCP $(\mathrm{N}=74)$ & $P$ value \\
\hline $\begin{array}{l}\text { Success rate } \\
\text { Technical }\end{array}$ & $198(85.7 \%)$ & & & \\
Clinical & $185(80.1 \%)$ & $94(81.0 \%)$ & $46(75.7 \%)$ & 0.120 \\
Post-ERCP adverse events & & $87(75.0 \%)$ & & 0.002 \\
Pancreatitis & $13(5.6 \%)$ & $5(4.3 \%)$ & $4(5.4 \%)$ & $0.5 \%)$ \\
Bleeding & $5(2.2 \%)$ & $3(2.6 \%)$ & $0(0.0 \%)$ & 0.404 \\
Perforation & $1(0.4 \%)$ & $0(0.0 \%)$ & $14.9 \pm 18.1$ & 0.662 \\
Hospital stay & $11.1 \pm 22.1$ & $12.1 \pm 12.7$ & 0.337 \\
\hline
\end{tabular}

$E R C P$ endoscopic retrograde cholangiopancreatography

$1(0.2 \%)$ patient. There were no significant differences in procedure-related adverse events between any of the study groups. Overall, the mean hospital stay was $12.1 \pm 19.2$ days, and there were no significant differences in any of the ERCP groups $(P=0.337)$.

\section{Discussion}

There is limited data evaluating the optimal timing of ERCP in patients with cholangitis caused by distal MBO. In this study, we analyzed the outcomes of urgent or early ERCP in acute cholangitis due to distal MBO. This study found that urgent ERCP clearly improved the 30-day 
mortality rate and the 180 -day mortality rate, especially in patients with primary $\mathrm{MBO}$ and moderate-to-severe cholangitis.

Even without considering the etiology, the optimal timing of ERCP in patients with acute cholangitis remains controversial. In a recent meta-analysis, in-hospital mortality was reduced when ERCP had been performed within $24 \mathrm{~h}$ as compared to after $24 \mathrm{~h}$, within $48 \mathrm{~h}$ as compared to after $48 \mathrm{~h}$, within $72 \mathrm{~h}$ as compared to after $72 \mathrm{~h}$ [25]. Another recent meta-analysis also demonstrated the beneficial effect of urgent or early ERCP on 30-day mortality [4]. These studies, however, were not able to separate the survival benefits to patients who had received urgent ERCP and early ERCP, because the mortality data for patients who had undergone ERCP between 24 and $48 \mathrm{~h}$ was reported inconsistently. We divided this study group into three independent groups according to the timing of the ERCP, and we selected the 30 -day and 180-day mortality rates as the primary outcomes, taking into account the subsequent treatments such as chemotherapy and curative surgery. The urgent ERCP group showed a significant improvement in both the 30-day mortality rate and 180-day mortality rate over the delayed ERCP group. Meanwhile, the differences in the 30-day and 180-day mortality rates between early and delayed ERCP groups were not statistically significant. This may be because of the nature of early ERCP but may also be because of an insufficient sample size.

In the Tokyo Guidelines, urgent or early ERCP is recommended for patients with moderate-to-severe cholangitis, and a large-scale observational study showed that urgent and early ERCP improved 30-day mortality in patients with moderate cholangitis [8]. In the case of mild cholangitis, however, biliary drainage should be considered when the initial supportive treatment shows insufficient response $[20,26]$. Our study found that the urgent ERCP improved the 30-day mortality rate, as well as the 180-day mortality rate, in moderate-to-severe cholangitis due to distal MBO. This implies that urgent ERCP can increase short-term and medium-term survival rates in the moderate-to-severe cholangitis group by minimizing disruption of subsequent treatment, including curative surgery and palliative chemotherapy for underlying malignant disease. Meanwhile, this survival benefit was limited in patients with mild cholangitis.

In this study, urgent ERCP improved the 30-day and 180-day mortality rates in the primary distal MBO group, whereas the differences of 30-day and 180-day mortality rates were not significant in the secondary distal $\mathrm{MBO}$ group. This indicates that urgent ERCP in the primary distal $\mathrm{MBO}$ group can improve both the short-term and medium-term outcomes by enabling a timely implementation of subsequent anticancer treatment, such as curative surgery and chemotherapy. In the secondary distal MBO group, however, these anticancer treatment attempts were difficult, even though biliary drainage was successful.

Because of anatomical alteration associated with tumor invasion or previous surgery, endoscopic access to the bile duct can be difficult in patients with distal MBO [15, 16, 27]. In a study of patients with distal MBO due to pancreatic head cancer, adequate drainage was successful in $75 \%$ of the cases in the first ERCP trial [28]. Although some randomized controlled trials reported a technical success rate of $90 \%$ or higher, few or no patients with a history of previous upper gastrointestinal surgery were included, and no information on previous ERCP history was available $[27,29]$. In the present study, the technical success rate was not inferior to previous studies, considering that some of the included patients had anatomical alterations due to previous surgery, and all patients with a previous ERCP history were excluded.

In this study, patients who visited ER on holidays tended to receive ERCP later, because the timing of ERCP was determined by each physician. In univariable and multivariable analysis, however, there were no significant differences in 30-day and 180-day mortality rates between those who visited on weekdays and weekends. This indicates that patients who needed the urgent biliary drainage were treated appropriately by the doctor's decision, regardless of the day of the hospital visit.

The doctors in this study preferred plastic stents when there was a possibility of curative treatment, and used metal stents when palliative chemotherapy or supportive care was expected. This tendency may affect the better 180-day mortality rate in plastic stent group.

There are several limitations in this study. First, this retrospective, single-center study may have inherent selection bias. Second, about half of the patients (54.9\%) underwent urgent ERCP following ER arrival, resulting in a smaller sample size of early and delayed ERCP groups. Caution needs to be applied when interpreting the results of subgroup analysis. Third, since more than half of the patients had not been diagnosed with cancer before ER arrival, comprehensive investigation of the Eastern Cooperative Oncology Group performance status could not be made at the time of ERCP. Instead, this study evaluated the $\mathrm{CCI}$, and provided information on the underlying disease status. Fourth, a variety of carcinomas were included in each group. Staging systems, treatment protocols, and prognoses are largely different for each cancer. This heterogeneity may serve as a confounding factor in outcomes analysis. Fifth, some clinical information, such as the cause of death, could not be analyzed because this was not accessible in the government data. Nevertheless, this 
study has the strength that it demonstrates therapeutic outcomes of urgent ERCP for acute cholangitis in patients with only distal MBO.

\section{Conclusions}

In conclusion, urgent ERCP might be performed actively in acute cholangitis caused by distal MBO considering the severity and etiology of the MBO. Welldesigned larger prospective randomized controlled trials are needed to evaluate the optimal timing of ERCP in patients with acute cholangitis due to distal $\mathrm{MBO}$.

\section{Abbreviations}

ERCP: Endoscopic retrograde cholangiopancreatography; MBO: Malignant biliary obstruction; ER: Emergency room; ICD-10: 10th edition of the International Classification of Diseases; CCl: Charlson's Comorbidity Index.

\section{Supplementary Information}

The online version contains supplementary material available at https://doi. org/10.1186/s12876-021-01755-z.

Additional file 1. The difference of 30-day mortality rate between urgent, early, and delayed ERCP groups in each subgroup.

Additional file 2 . The difference of 180-day mortality rate between urgent, early, and delayed ERCP groups in each subgroup.

\section{Acknowledgements}

None.

\section{Authors' contributions}

NP contributed to data collection, statistical analysis and draft of the manuscript; SHL conceptualized and designed the study and interpreted and draft the manuscript; MSY contributed to study design and data collection; JSK participated in the data collection, statistical analysis, and manuscript writing; GH, JWC, and IRC contributed to data analysis and manuscript writing; WHP, JKR, and YTK performed data acquisition and contributed to manuscript writing. All authors read and approved the final manuscript.

\section{Funding}

Not applicable

\section{Availability of data and materials}

The datasets used and/or analyzed during the current study are available from the corresponding author upon reasonable request.

\section{Declarations}

\section{Ethics approval and consent to participate}

Prior to data collection, this study was approved by the Institutional Review Board of Seoul National University Hospital. Consent to participate was waived by the institutional review board because this study was retrospective study and all patient information had been unidentifiable.

\section{Consent for publication}

Not applicable.

\section{Competing interests}

The authors declare that they have no competing interests.
Received: 14 January 2021 Accepted: 7 April 2021

Published online: 17 April 2021

\section{References}

1. Boey JH, Way LW. Acute cholangitis. Ann Surg. 1980;191(3):264-70.

2. Gigot JF, Leese T, Dereme T, Coutinho J, Castaing D, Bismuth H. Acute cholangitis: multivariate analysis of risk factors. Ann Surg. 1989;209(4):435-8.

3. Hou LA, Laine L, Motamedi N, Sahakian A, Lane C, Buxbaum J. Optimal timing of endoscopic retrograde cholangiopancreatography in acute cholangitis. J Clin Gastroenterol. 2017;51(6):534-8.

4. Iqbal U, Khara HS, Hu Y, Khan MA, Ovalle A, Siddique O, Sun H, Shellenberger MJ. Emergent versus urgent ERCP in acute cholangitis: a systematic review and meta-analysis. Gastrointest Endosc. 2020;91(4):753-60.

5. Lee F, Ohanian E, Rheem J, Laine L, Che K, Kim JJ. Delayed endoscopic retrograde cholangiopancreatography is associated with persistent organ failure in hospitalised patients with acute cholangitis. Aliment Pharmacol Ther. 2015;42(2):212-20.

6. Chak A, Cooper GS, Lloyd LE, Hammar PJ, Issa K, Rosenthal GE. Effectiveness of ERCP in cholangitis: a community-based study. Gastrointest Endosc. 2000;52(4):484-9.

7. Mulki R, Shah R, Qayed E. Early vs late endoscopic retrograde cholangiopancreatography in patients with acute cholangitis: a nationwide analysis. World J Gastrointest Endosc. 2019;11(1):41-53.

8. Kiriyama S, Takada T, Hwang TL, Akazawa K, Miura F, Gomi H, Mori R, Endo I, Itoi T, Yokoe M, et al. Clinical application and verification of the TG13 diagnostic and severity grading criteria for acute cholangitis: an international multicenter observational study. J Hepatobiliary Pancreat Sci. 2017:24(6):329-37.

9. Navaneethan U, Gutierrez NG, Jegadeesan R, Venkatesh PG, Butt M, Sanaka MR, Vargo JJ, Parsi MA. Delay in performing ERCP and adverse events increase the 30-day readmission risk in patients with acute cholangitis. Gastrointest Endosc. 2013;78(1):81-90.

10. Lai ECS, Mok FPT, Tan ESY, Lo C-M, Fan S-T, You K-T, Wong J. Endoscopic biliary drainage for severe acute cholangitis. N Engl J Med. 1992;326(24):1582-6.

11. Conroy T, Hammel P, Hebbar M, Ben Abdelghani M, Wei AC, Raoul J-L, Choné L, Francois E, Artru P, Biagi JJ, et al. FOLFIRINOX or gemcitabine as adjuvant therapy for pancreatic cancer. N Engl J Med. 2018:379(25):2395-406.

12. Von Hoff DD, Ervin T, Arena FP, Chiorean EG, Infante J, Moore M, Seay T, Tjulandin SA, Ma WW, Saleh MN, et al. Increased survival in pancreatic cancer with nab-paclitaxel plus gemcitabine. N Engl J Med. 2013:369(18):1691-703.

13. Valle J, Wasan H, Palmer DH, Cunningham D, Anthoney A, Maraveyas A, Madhusudan S, Iveson T, Hughes S, Pereira SP, et al. Cisplatin plus gemcitabine versus gemcitabine for biliary tract cancer. N Engl J Med. 2010;362(14):1273-81.

14. Parikh MP, Garg R, Chittajallu V, Gupta N, Sarvepalli S, Lopez R, Thota PN, Siddiki H, Bhatt A, Chahal P, et al. Trends and risk factors for 30-day readmissions in patients with acute cholangitis: analysis from the national readmission database. Surg Endosc. 2020;35:223-31.

15. Aadam AA, Liu K. Endoscopic palliation of biliary obstruction. J Surg Oncol. 2019;120(1):57-64.

16. Dhir V, Itoi T, Khashab MA, Park DH, Teoh AYB, Attam R, Messallam A, Varadarajulu S, Maydeo A. Multicenter comparative evaluation of endoscopic placement of expandable metal stents for malignant distal common bile duct obstruction by ERCP or EUS-guided approach. Gastrointest Endosc. 2015;81(4):913-23.

17. Boulay BR, Birg A. Malignant biliary obstruction: from palliation to treatment. World J Gastroint Oncol. 2016;8(6):498-508.

18. Jang SE, Park SW, Lee BS, Shin CM, Lee SH, Kim J-W, Jeong S-H, Kim $\mathrm{N}$, Lee DH, Park JK, et al. Management for CBD stone-related mild to moderate acute cholangitis: urgent versus elective ERCP. Dig Dis Sci. 2013;58(7):2082-7.

19. Tan M, Schaffalitzky de Muckadell OB, Laursen SB. Association between early ERCP and mortality in patients with acute cholangitis. Gastrointest Endosc. 2018:87(1):185-92. 
20. Kiriyama S, Kozaka K, Takada T, Strasberg SM, Pitt HA, Gabata T, Hata J, Liau KH, Miura F, Horiguchi A, et al. Tokyo guidelines 2018: diagnostic criteria and severity grading of acute cholangitis (with videos). J Hepatobiliary Pancreat Sci. 2018;25(1):17-30.

21. Parikh MP, Wadhwa V, Thota PN, Lopez R, Sanaka MR. Outcomes associated with timing of ERCP in acute cholangitis secondary to choledocholithiasis. J Clin Gastroenterol. 2018;52(10):e97-102.

22. Chung KH, Lee SH, Park JM, Lee JM, Ahn DW, Ryu JK, Kim YT. Self-expandable metallic stents vs. plastic stents for endoscopic biliary drainage in hepatocellular carcinoma. Endoscopy. 2015;47(6):508-16.

23. Cotton PB, Eisen GM, Aabakken L, Baron TH, Hutter MM, Jacobson BC, Mergener K, Nemcek A, Petersen BT, Petrini JL, et al. A lexicon for endoscopic adverse events: report of an ASGE workshop. Gastrointest Endosc. 2010;71(3):446-54.

24. Venables WNRB. Modern applied statistics with S. 4th ed. New York: Springer; 2002

25. Du L, Cen M, Zheng X, Luo L, Siddiqui A, Kim JJ. Timing of performing endoscopic retrograde cholangiopancreatography and inpatient mortality in acute cholangitis: a systematic review and meta-analysis. Clin Transl Gastroenterol. 2020;11(3):e00158.
26. Tsuchiya T, Sofuni A, Tsuji S, Mukai S, Matsunami Y, Nagakawa Y, Itoi T. Endoscopic management of acute cholangitis according to the TG13. Dig Endosc. 2017;29:94-9.

27. Paik WH, Lee TH, Park DH, Choi J-H, Kim S-O, Jang S, Kim DU, Shim JH, Song TJ, Lee SS, et al. EUS-Guided biliary drainage versus ERCP for the primary palliation of malignant biliary obstruction: a multicenter randomized clinical trial. Am J Gastroenterol. 2018;113(7):987-97.

28. van der Gaag NA, Rauws EAJ, van Eijck CHJ, Bruno MJ, van der Harst E, Kubben FJGM, Gerritsen JJGM, Greve JW, Gerhards MF, de Hingh IHJT, et al. Preoperative biliary drainage for cancer of the head of the pancreas. N Engl J Med. 2010;362(2):129-37.

29. Park JK, Woo YS, Noh DH, Yang J-I, Bae SY, Yun HS, Lee JK, Lee KT, Lee KH. Efficacy of EUS-guided and ERCP-guided biliary drainage for malignant biliary obstruction: prospective randomized controlled study. Gastrointest Endosc. 2018;88(2):277-82.

\section{Publisher's Note}

Springer Nature remains neutral with regard to jurisdictional claims in published maps and institutional affiliations.
Ready to submit your research? Choose BMC and benefit from:

- fast, convenient online submission

- thorough peer review by experienced researchers in your field

- rapid publication on acceptance

- support for research data, including large and complex data types

- gold Open Access which fosters wider collaboration and increased citations

- maximum visibility for your research: over $100 \mathrm{M}$ website views per year

At BMC, research is always in progress.

Learn more biomedcentral.com/submissions 